\title{
Coverage of Transmission of COVID-19 Information on Successive Samples of YouTube Videos
}

\author{
Grace C. Hillyer ${ }^{1}\left[\right.$ ] Corey H. Basch ${ }^{2}$. Charles E. Basch ${ }^{3}$
}

Accepted: 10 December 2020 / Published online: 5 January 2021

(C) The Author(s), under exclusive licence to Springer Science+Business Media, LLC part of Springer Nature 2021

\begin{abstract}
Mitigating transmission of SARS-Co-2 virus is critical to stopping the COVID-19 pandemic. Messages about the pandemic on YouTube reach millions of people and should be a part of a more comprehensive strategy for educating the public to reduce transmission. We examined successive samples of the 100 most widely viewed YouTube videos regarding COVID-19 at three time points between January and June 2020 and examined characteristics of videos that specifically mentioned COVID19 transmission. We described the cumulative and mean number of views, video length, and video source and assessed differences across the samples. Historical events and confirmed worldwide cases are compared with cumulative views of videos mentioning disease transmission over time. Across the three successive samples, views for all videos increased from $\sim 125$ million to over 560 million views, and from $\sim 63$ million to more than 273 million for those videos specifically mentioning disease transmission, respectively. This increase coincided with the increase in the worldwide number of cases and the occurrence of COVID-19 transmission informational milestones. Despite its importance for community mitigation, the majority of the widely viewed videos we sampled did not specifically mention disease transmission. Because of its very widespread reach, YouTube can be an effective way to communicate with the public, especially to those who have lower levels of reading literacy and who may be inclined to search for information on YouTube. Greater efforts are needed to more fully realize the potential of YouTube for educating the public about COVID-19 transmission.
\end{abstract}

Keywords COVID-19 $\cdot$ Pandemic $\cdot$ Transmission of infectious disease $\cdot$ Social media $\cdot$ YouTube

\section{Introduction}

In late December 2019, news had broken that a respiratory illness of unknown origin had emerged in Wuhan, China [1]. Over time, the illness would be named COVID-19, and determined to be caused by the virus SARS-CoV-2 [2, 3]. COVID-19 spiraled out of control, reaching pandemic status by March 11, 2020 [4] and, globally, as of October 18, 2020,

Grace C. Hillyer

gah28@cumc.columbia.edu

1 Department of Epidemiology, Mailman School of Public Health, Columbia University, 722 W. 168th Street, Room 1611, New York, NY 10032, USA

2 Department of Public Health, William Paterson University, 300 Pompton Road, Wayne, NJ 07470, USA

3 Department of Health and Behavior Studies, Teachers College, Columbia University, 525 W. 125th Street, New York, NY 10027, USA has infected more than 39 million individuals and caused over 1,100,000 deaths [5].

The public has been bombarded with information about COVID-19 online, on television, and in the press. A steady stream of communication to inform the public about supply shortages, lack of testing and treatment resources, imposition of "stay at home" orders and quarantining, and looming financial and economic crises have dominated the public's attention. Still, the pandemic rages on due in large part to lack of mitigation of transmission.

Early mitigation messaging focused primarily on handwashing, with little attention given to promotion of wearing masks and the potential airborne human-to-human transmission of the disease. In the United States, the public was discouraged from using or stockpiling personal protective equipment (PPEs), including masks, to reserve the inadequate supply for first-line workers and medical personnel [6]. Understanding various modes of transmission and communicating effectively about ways to interrupt transmission are essential to combat this public health crisis. One of the 
main avenues by which such information can be conveyed to the public is through social media, which has been used to share information about various emerging infectious diseases [7-12]. The purpose of this study was to examine three successive samples of the 100 most widely viewed YouTube videos regarding COVID-19 January, April, and June 2020 and determine the characteristics of videos that specifically mentioned disease transmission.

\section{Methods}

At three different data collection points in 2020 (Round 1, January 31; Round 2, April 30; and Round 3, June 30), YouTube videos were selected using the keyword "Coronavirus" and sorted by view count to identify the 100 most widely viewed videos in Spanish and English. Each video was coded dichotomously (yes, no) based on whether disease transmission was mentioned. All coding was conducted by the same two individuals. Additional data coded for each video included date and source of upload, length of the video (in minutes), and number of views. Analysis comprised descriptive statistics (frequencies and percentages) for categorical variables and means with standard deviations and ranges for continuous variables. All analyses were performed using IBM SPSS version 27 [13]. The Institutional Review Boards at Columbia University and William Paterson University do not review non-human subjects' studies. The Institutional Review Board at Teachers College, Columbia University deemed this study as exempt.

\section{Results}

Across the three successive samples we examined, the total cumulative views increased from $\sim 125$ million to over 560 million views, which demonstrated the considerable reach of YouTube for communicating with the public about COVID-19 (Table 1). Despite the importance of information about transmission of SARS-CoV-2, the majority of videos within each sample did not specifically mention disease transmission. While the number of videos mentioning transmission did not vary dramatically from the first sample in January to the third sample in June (42\%, 46\%, and 40\%, respectively), there was more than a four-fold increase in the cumulative views these videos received (from $\sim 63$ million to more than 273 million).

Figure 1 presents the number of views at each of the three time points in the context of the ascent of worldwide confirmed cases and the release of critical transmission information as the pandemic unfolded over the course of this 6-month period [14-19]. There were no significant differences between the three successive samples regarding mean length of the videos, source, or language. There were only six videos from the first sample that were still among the 100 most widely viewed in the second sample, but there were 48 videos in second sample that were retained in third.

\section{Discussion}

This successive sampling study extended our prior work examining coverage of COVID-19 prevention behaviors on YouTube [20, 21]. We examined the extent to which three successive samples of the 100 most widely viewed videos about COVID-19 mentioned disease transmission during the early phase of the pandemic (January to June 2020). Our findings show a dramatic increase in views of YouTube videos covering the transmission of COVID-19 from the early months of 2020 (Sample 1) to the spring and summer of 2020 (Samples 2 and 3, respectively) that coincides both with the mounting numbers of confirmed COVID-19 cases worldwide and the release of SARS-Co-V2 transmission information in this period.

Over the past century, the epidemiologic triad model has demonstrated that transmission of infectious diseases results from the interaction of an agent, a host, and the environment [22]. Until understanding of these factors is well understood in an outbreak, it is challenging to establish criteria to reduce exposure and susceptibility. In the early days of the pandemic, widely viewed English and Spanish language YouTube videos were lacking in information related to COVID-19 [21]. Mention of mask use was minimal at first, later evolving into recommendations and mandates for widespread mask use beginning April 3, 2020 [23, 24] as shortages of masks for health care workers were addressed and the literature supporting airborne transmission mounted along with evidence that masking was associated with declines in COVID-19 positive tests [25], and daily reported cases [26]. In contrast, earlier messaging focused on hand washing and disinfecting spaces in addition to avoiding those who were ill.

This study is limited in several respects. Algorithms used by YouTube to filter that most widely viewed videos may have changed during the study period [27]. We only sampled videos in two languages, English, and Spanish. Only 100 videos were included in each of three samples; a larger number of samples or videos included in each sample may 
Table 1 Characteristics of YouTube videos that mention COVID-19 transmission $(n=128)$ over the course of 3 rounds of evaluation (January through June 2020)

\begin{tabular}{|c|c|c|c|}
\hline & \multicolumn{3}{|l|}{ Round } \\
\hline & 1 & 2 & 3 \\
\hline & $\mathrm{N}(\%)$ & $\mathrm{N}(\%)$ & $\mathrm{N}(\%)$ \\
\hline \multicolumn{4}{|l|}{ Total } \\
\hline Number videos & 100 & 100 & 100 \\
\hline Video views & $125,286,561$ & $508,123,042$ & $561,652,828$ \\
\hline \multicolumn{4}{|l|}{ Transmission } \\
\hline Number videos & 42 & 46 & 40 \\
\hline Video views & $\begin{array}{l}63,474,010 \\
(50.7)\end{array}$ & $\begin{array}{l}263,132,046 \\
(51.8)\end{array}$ & $\begin{array}{l}273,652,313 \\
(48.7)\end{array}$ \\
\hline Mean views $[\mathrm{SD}]$ & $1,511,286[1,162,742]$ & $5,720,262[4,396,297]$ & $6,841,308[5,589,645]$ \\
\hline Range & $\begin{array}{l}506,008 \\
-6,210,622\end{array}$ & $1,653,232-22,316,264$ & $1,662,930-25,498,934$ \\
\hline \multicolumn{4}{|l|}{ Video length } \\
\hline Mean length [SD] (minutes) & $8.3[6.3]$ & $10.7[10.7]$ & $11.8[11.3]$ \\
\hline Range & $0.15-29.4$ & $2.1-51.5$ & $2.1-51.5$ \\
\hline \multicolumn{4}{|l|}{ Source } \\
\hline Consumer & $5(11.9)$ & $12(26.1)$ & $7(17.5)$ \\
\hline Professional & $6(14.3)$ & $3(6.5)$ & $6(15.0)$ \\
\hline Television & $22(52.4)$ & $28(60.9)$ & $24(60.0)$ \\
\hline Internet & $9(21.4)$ & $3(6.5)$ & $3(7.5)$ \\
\hline \multicolumn{4}{|l|}{ Video language } \\
\hline English & $32(76.2)$ & $38(82.6)$ & $36(90.0)$ \\
\hline Spanish & $8(19.0)$ & $8(17.4)$ & $4(10.0)$ \\
\hline Other & $2(4.8)$ & $0(0.0)$ & $0(0.0)$ \\
\hline
\end{tabular}

have yielded different results. Many persons who post videos on YouTube to share information about topics as serious as COVID-19 have varying levels of expertise that may influence the quality of the information communicated. While we coded specific mentions of COVID-19 transmission, it was beyond the scope of this study to evaluate the veracity of the information sources. Information about the transmission of COVID-19 is still evolving; early on in the pandemic use of masks was not recommended for the general public but now they are, and what information is considered "accurate" has and continues to evolve and is dependent on what individuals and groups are making this determination. Regardless of these limitations, this study contributes to the literature regarding the importance of studying social media over time.

Even though YouTube is heavily consumer driven, the findings from this study adds to an emerging body of literature showing how and why public health professionals should use YouTube as a communication channel to educate the public. While YouTube can spread false information, because of its widespread reach it can be an effective way to communicate with the public, especially those who have lower levels of reading literacy and may be inclined to search for information using video communication. Public health professionals can partner with influential individuals within communities to dispel myths and provide up-to-date accurate information to help people make informed decisions about reducing exposure and susceptibility. To date, COVID-19 caused by SARS-Co-V-2 is the fifth documented pandemic following the 1918 Spanish flu (H1N1), the 1957 Asian flu (H2N2), the 1968 Hong Kong flu (H3N2), the 2009 Pandemic flu (H1N1), with 50 million, 1.5 million, 1 million and 300,000 deaths, respectively [28]. As research points to the fact that written material on this topic is often difficult to read [29], public health education on YouTube can be an important element of a more comprehensive strategy to community mitigation efforts. 


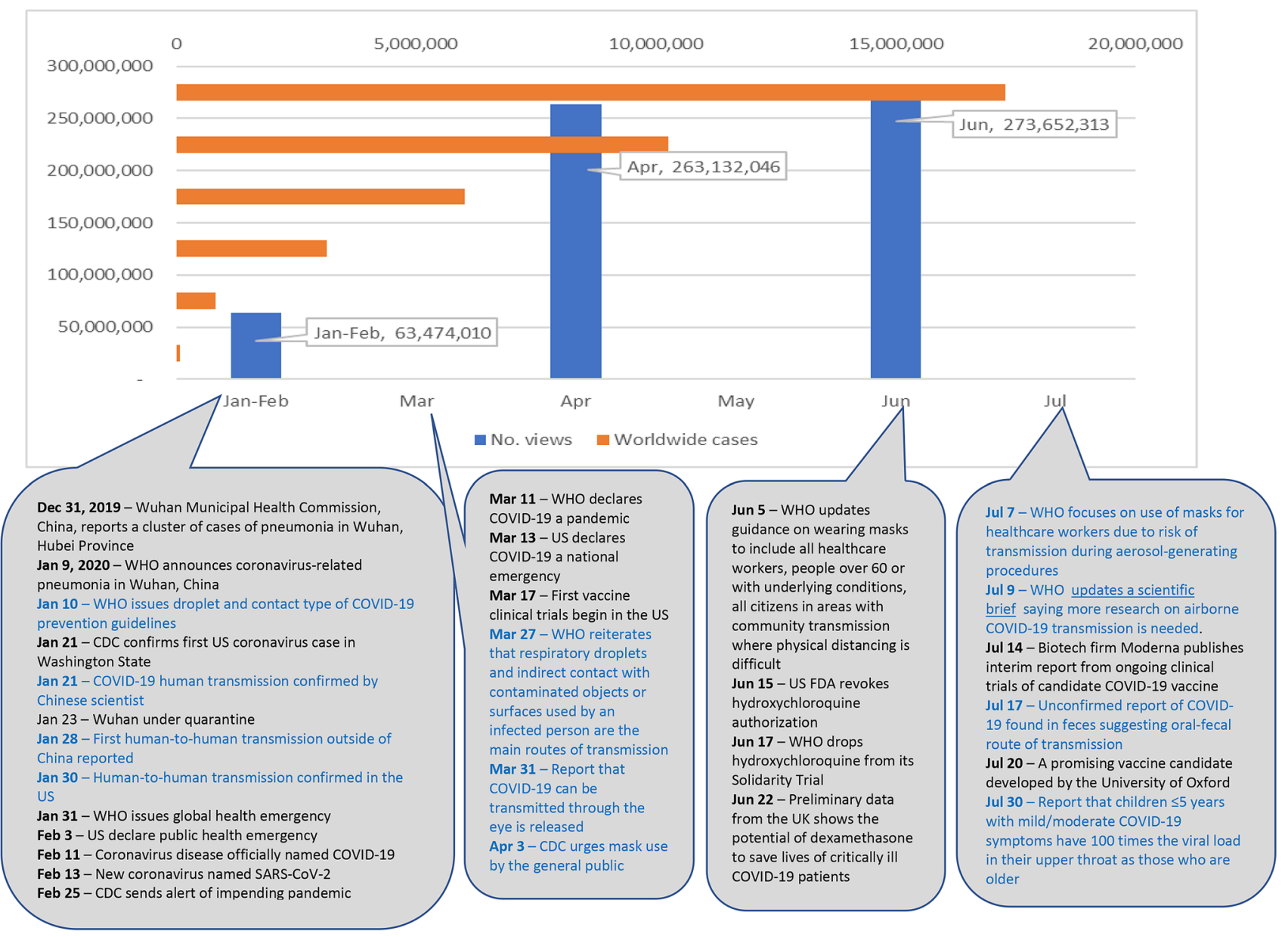

Fig. 1 Number of cumulative views of YouTube videos about COVID-19 transmission by time, worldwide confirmed cases and historicalevents related to the COVID-19 pandemic

Acknowledgements The authors would like to thank C. Jaime for her work on this and prior iterations of this project.

\section{Funding None.}

\section{Compliance with Ethical Standards}

Conflict of Interest None of the authors report a conflict of interest.

Ethical approval The Institutional Review Boards at Columbia University and William Paterson University do not review non-human subjects' studies. The Institutional Review Board at Teachers College, Columbia University deemed this study as exempt.

\section{References}

1. Zhu, N., Zhang, D., Wang, W., Li, X., Yang, B., Song, J., et al. (2020). A novel coronavirus from patients with pneumonia in China, 2019. The New England Journal of Medicine, 328(8), 727-733.
2. Sohrabi, C., Alsafi, Z., O’Neill, N., Khan, M., Kerwan, A., AlJabir, A., et al. (2020). Corrigendum to World Health Organization declares Global Emergency: A review of the 2019 Novel Coronavirus (COVID-19). International Journal of Surgery 76, 71-76]. .77:217.

3. Sohrabi, C., Alsafi, Z., O’Neill, N., Khan, M., Kerwan, A., AlJabir, A., et al. (2020). World Health Organization declares global emergency: A review of the 2019 novel coronavirus (COVID-19). International Journal of Surgery, 76, 71-76.

4. World Health Organization (WHO). (2020). WHO Director-General's opening remarks at the media briefing on COVID-19-11 March 2020. Retrieved August 10, 2020, from https://www.who. $\mathrm{int} / \mathrm{dg} / \mathrm{speeches/detail/who-director-general-s-opening-remarks-}$ at-the-media-briefing-on-covid-19--11-march-2020.

5. Johns Hopkins University \& Medicine. (2020). Coronavirus Resource Center. Retrieved May 24, 2020, from https://coron avirus.jhu.edu/map.html.

6. Ranney, M. L., Griffeth, V., \& Jha, A. K. (2020). Critical supply shortages - The need for ventilators and personal protective equipment during the Covid-19 pandemic. The New England Journal of Medicine, 30(18), e41.

7. Freberg, K., Palenchar, M. J., \& Veil, S. R. (2013). Managing and sharing H1N1 crisis information using social media bookmarking services. Public Relations Review, 39, 178-184. 
8. Biswas, M. (2013). Health organizations' use of social media tools durng a pandemic situation: an H1N1 flu context. Journal of New Communication Research, 5, 46-81.

9. Tang, L., Bie, B., \& Zhi, D. (2018). Tweeting about measles during stages of an outbreak: A semantic network approach to the framing of an emerging infectious disease. American Journal of Infection Control, 46(12), 1375-1380.

10. Basch, C. H., Basch, C. E., Ruggles, K. V., \& Hammond, R. (2015). Coverage of the Ebola Virus disease epidemic on YouTube. Disaster Medicine and\&nbsp;Public Health Preparedness, 9(5), 531-535.

11. Basch, C. H., Fung, I. C. H., Hammond, R. N., Blankenship, E. B., Tse, Z. T. H., Fu, K.-W., et al. (2017). Zika Virus on YouTube: An analysis of English-language video content by source. Journal of Preventive Medicine and Public Health, 50(2), 133-140.

12. Dubey, D., Amritphale, A., Sawhney, A., Dubey, D., \& Srivastav, N. (2014). Analysis of YouTube as a source of information for West Nile Virus infection. Clinical Medicine and Research, 12(3-4), 129-132.

13. IBM Corp. (2020). IBM SPSS Statistics for Windows, Version 27.0. Armonk: IBM Corp.

14. (2020). Coronavirus: the first three months as it happened. Nature. Retrieved August 28, 2020, from https://www.nature.com/articles/ d41586-020-00154-w.

15. American Journal of Managed Care Staff. (2020). A timeline of COVID-19 developments in 2020. Retrieved August 10, 2020, from https://www.ajmc.com/view/a-timeline-of-covid19-devel opments-in-2020.

16. World Health Organization (WHO). (2020). Archived: WHO timeline - COVID-19. Retrieved August 10, 2020, from https:// www.who.int/news-room/detail/27-04-2020-who-timeline---covid -19 .

17. Ravelo, J. L., \& Jerving, S. (2020). COVID-19 - a timeline of the coronavirus outbreak. Retrieved August 10, 2020, from https ://www.devex.com/news/covid-19-a-timeline-of-the-coronaviru s-outbreak-96396.

18. Our World in Data. (2020). United States: Coronavirus pandemic. Retrieved August 10, 2020, from https://ourworldindata.org/coron avirus/country/united-states?country= USA\#cumulative-confi rmed-cases-how-rapidly-have-they-increased-compared-to-other -countries.

19. Our World in Data. (2020). Statistics and research: Coronavirus pandemic (COVID-19). Retrieved August 10, 2020, from https:// ourworldindata.org/coronavirus\#coronavirus-country-profiles.
20. Basch, C. E., Basch, C. H., Hillyer, G. C., \& Jaime, C. (2020). The role of YouTube and the entertainment industry in saving lives by educating and mobilizing the public to adopt behaviors for community mitigation of COVID-19: Successive sampling design study. JMIR Public Health and Surveillance., 6(2), e19145.

21. Basch, C. H., Hillyer, G. C., Meleo-Erwin, Z. C., Jaime, C., Mohlman, J., \& Basch, C. E. (2020). Preventive behaviors conveyed on YouTube to mitigate transmission of COVID-19: Cross-sectional study. JMIR Public Health and Surveillance, 6(2), e18807.

22. Centers for Disease Control and Prevention. An introduction to applied epidemiology and biostatistics: Lession 1: Introduction to epidemiology; Sect. 10: Chain of infection. Principles of epidemiology in public health, Third edition2012. p. https://www.cdc. gov/csels/dsepd/ss1978/lesson1/section10.html.

23. Centers for Disease Control and Prevention. (2020). Coronavirus disease 2019 (COVID-19): Considerations for wearing masks Help slow the spread of COVID-19. Retrieved September 12, 2020, from https://www.cdc.gov/coronavirus/2019-ncov/preve nt-getting-sick/cloth-face-cover-guidance.html.

24. Gostin, L. O., Cohen, G., \& Koplan, J. P. (2020). Universal masking in the United States: The role of mandates, health education, and the CDC. JAMA, 324(9), 837-838.

25. Wang, X., Ferro, E. G., Zhou, G., Hashimoto, D., \& Bhatt, D. L. $(2020 \mathrm{Jul})$. Association between universal masking in a health care system and SARS-CoV-2 positivity among health care workers. JAMA, 14(7), 703-704. 324(.

26. Lyu, W., \& Wehby, G. L. (2020). Community use of face masks and COVID-19: Evidence from a natural experiment of state mandates in the U.S. Health Affairs (Millwood)., 39(8), 1419-25.

27. The YouTube Team. (2020). Protecting our extended workforce and the community. Retrieved September 12, 2020, from https ://blog.youtube/news-and-events/protecting-our-extended-workf orce-and.

28. Liu, Y.-C., Kuo, R.-L., \& Shih, S.-R. (2020). COVID-19: The first documented coronavirus pandemic in history. Biomedicine Journal, 43(4), 328-333.

29. Basch, C. H., Mohlman, J., Hillyer, G. C., \& Garcia, P. (2020). Public health communication in time of crisis: Readability of online COVID-19 information. Disaster Medicine \& Public Health Preparedness, 11, 1-3.

Publisher's Note Springer Nature remains neutral with regard to jurisdictional claims in published maps and institutional affiliations. 